\title{
Perioperative Cardiac Complications in Patients Over 80 Years of Age with Coronary Artery Disease Undergoing Noncardiac Surgery: The Incidence and Risk Factors
}

This article was published in the following Dove Press journal:

Clinical Interventions in Aging

\author{
Zijia Liu (D) ${ }^{\prime}$ \\ Guangyan Xu' \\ Li Xu ${ }^{\prime}$ \\ Yuelun Zhang ${ }^{2}$ \\ Yuguang Huang' \\ 'Department of Anesthesiology, Peking \\ Union Medical College Hospital, Chinese \\ Academy of Medical Sciences and Peking \\ Union Medical College, Beijing 100730, \\ People's Republic of China; ${ }^{2}$ Central \\ Research Laboratory, Peking Union \\ Medical College Hospital, Chinese \\ Academy of Medical Sciences and Peking \\ Union Medical College, Beijing 100730, \\ People's Republic of China
}

Purpose: Ever-increasing noncardiac surgeries are performed in patients aged 80 years or over with coronary artery disease (CAD). The objective of the study was to explore the incidence and risk factors of perioperative cardiac complications (PCCs) for the oldest-old patients with CAD undergoing noncardiac surgery, which have not been evaluated previously.

Patients and Methods: A total of 547 patients, aged over 80 years, with a history of CAD who underwent noncardiac surgery were enrolled in this retrospective study. Perioperative clinical variables were extracted from the electronic medical records database. The primary outcome was the occurrence of PCCs intraoperatively or within 30 days postoperatively, defined as any of the following complications: acute coronary syndrome, heart failure, newonset severe arrhythmia, nonfatal cardiac arrest, and cardiac death. Multivariate logistic regression analysis and multivariate Cox regression model were both performed to estimate the risk factors of PCCs. The incidence of PCCs overtime was illustrated by the KaplanMeier curve with a stratified Log-rank test.

Results: One hundred six (19.4\%) patients developed at least one PCC, and $15(2.7 \%)$ patients developed cardiac death. The independent risk factors contributing to PCCs were age $\geqq 85$ years; body mass index $\geqq 30 \mathrm{~kg} / \mathrm{m}^{2}$; the history of angina within 6 months; metabolic equivalents $<4$; hypertension without regular treatment; preoperative ST-T segment abnormality; anesthesia time $>3 \mathrm{~h}$ and drainage $\geqq 200 \mathrm{~mL}$ within $24 \mathrm{~h}$ postoperatively. Conclusion: The incidence of PCCs in elderly patients over 80 years with CAD who underwent noncardiac surgery was high. Comprehensive preoperative evaluation, skilled surgical technique, and regular postoperative monitoring may help to reduce the occurrence of PCCs in this high-risk population.

Keywords: oldest-old, coronary artery disease, noncardiac surgery, perioperative, cardiac complications

\section{Introduction}

Worldwide, more than 300 million major noncardiac surgeries are performed every year and the number is increasing continuously. ${ }^{1}$ Cardiac complications are the most important causes of morbidity and mortality in the first 30 days after noncardiac surgery which result in prolonged length of stay, increased health care costs and poorer prognosis, ${ }^{2}$ and associate with perioperative factors, including
Correspondence: $\mathrm{Li} \mathrm{Xu}$

Tel +861069152020

Fax +861069155580

Email pumchxuli@I63.com 
advanced age, coronary artery disease (CAD), renal insufficiency, diabetes, congestive heart failure (HF), types of surgery and other conditions. ${ }^{3-5}$ Many studies have shown that advanced age and CAD provide substrate for cardiac complications after surgery. ${ }^{6-8}$ So elderly patients with CAD have a significantly increased risk of perioperative cardiac complications (PCCs). We have previously conducted a multicenter prospective study that enrolled 1422 elderly patients over 60 years old with CAD to determine the risk factors of PCCs undergoing noncardiac surgery. ${ }^{9}$

As global population aging, the proportion of people aged 80 years or over, defined as the oldest-old persons, is growing even faster than the number of elder persons overall. ${ }^{10}$ While the population of those aged over 65 years is expected to increase by $160 \%$ between 2008 and 2040, those aged over 80 years will increase by $233 \% .{ }^{11}$ The number of people aged 80 years or over in China is expected to increase by fourfold in 2050, representing the world's largest portion of this most elderly age group. ${ }^{12}$ Meanwhile, the prevalence and severity of CAD increase significantly with age. ${ }^{13}$ Currently, with the introduction of minimally invasive surgical techniques, combined with changes in anesthetic practices, and the introduction of "enhanced recovery after surgery" strategy, the number of surgical procedures for patients over 80 years old with CAD is increasing. ${ }^{14}$

Poor physiological changes are common in the oldest-old persons presenting with $\mathrm{CAD}$ and other complex comorbidities, which could complicate noncardiac operations and negatively impact outcomes. ${ }^{15}$ The risk of cardiac complications is rising with the average age increased from 60 years old to 80 years old. ${ }^{6}$ Not only that, the incidence characteristics and risk factors of PCCs in noncardiac surgery in the oldest-old population could be also partially different from those in the population over 60 according to our previous studies, as well as in the general population. Better risk indicators are imperative to be evaluated for the improvement of preoperative cardiac risk prediction for the oldest-old patients.

Therefore, we conducted this retrospective study based on the data from 2004 to 2019, to investigate the incidence and risk factors of PCCs in patients aged 80 years or over with $\mathrm{CAD}$ who underwent elective intermediate to high-risk noncardiac surgery. It would allow a better understanding of the benefit-to-risk ratio for procedures, optimize the perioperative management, determine the surgical strategy, guide allotment of limited clinical resources, and improve the quality of health care for the oldest-old persons.

\section{Methods}

\section{Study Population}

This single-center retrospective study was conducted to explore PCCs and mortality in elderly patients over 80 years old with $\mathrm{CAD}$, who underwent elective noncardiac surgery in Peking Union Medical College Hospital (PUMCH) from January 1, 2004, to December 31, 2019. Ethical consent was approved by the Ethics Committee and Institutional Review Board of PUMCH (No. of ethical approval: S-K1212). We conducted this study in accordance with the Declaration of Helsinki. The data were anonymized before analysis. Informed consent was waived. The types of surgery were elective intermediate to high-risk noncardiac surgery based on the American College of Cardiology (ACC)/American Heart Association (AHA) guidelines of perioperative cardiovascular evaluation. ${ }^{16} \mathrm{CAD}$ was diagnosed if any of the following conditions were met: CAD confirmed by coronary angiography, history of myocardial infarction (MI), history of coronary revascularization, positive myocardial perfusion scintigraphy, positive exercise stress test, or typical symptoms of angina pectoris with simultaneous signs of myocardial ischemia on the electrocardiograph (ECG). ${ }^{17}$

Exclusion criteria included: emergency surgery; local anesthesia; low-risk surgery, including eye surgery, endoscopic surgery (transurethral prostatic resection was not excluded), superficial surgery, and ambulatory surgery; patients with the American Society of Anesthesiologists (ASA) classification V or VI; patients complicated with other heart diseases (such as rheumatic heart disease, congenital heart disease, cardiomyopathy, or pulmonary heart disease); patients who underwent two operations or more during the same hospitalization.

\section{Clinical Care and Monitoring}

All patients were evaluated by routine preoperative assessment. The examination included at least 12-lead ECG, transthoracic echocardiography, and complete laboratory tests, otherwise, the patient would be excluded.

Intraoperative routine monitoring included blood pressure (BP), pulse oxygen saturation $\left(\mathrm{SpO}_{2}\right)$, 3-lead ECG and end tidal $\mathrm{CO}_{2}$ by mass spectroscopy. Intraoperative hypotension was defined as SBP $<90 \mathrm{mmHg}$ or $70 \%$ of the baseline value, or DBP $<60 \mathrm{mmHg}$, which lasted at least $10 \mathrm{~min}$. Intraoperative hypoxemia was defined as $\mathrm{SpO}_{2}$ $<90 \%$ or arterial partial pressure of oxygen $<60 \mathrm{mmHg}$ lasting over $5 \mathrm{~min}$. 
Postoperatively, continuous ECG monitoring was obtained for at least $12 \mathrm{~h}$ after surgery. A 12-lead ECG was implemented when indicated. Cardiac troponin I (cTnI) levels were measured when ECG changed or suspicious symptoms of PCCs developed, such as dyspnea or chest pain.

\section{Data Collection}

The electronic medical record system in PUMCH was used in this study. We identified all discharges over 80 years from the surgery department with a diagnosis of CAD. Further manual screening of medical records was performed according to inclusion/exclusion criteria. Clinical data were extracted retrospectively from electronic medical records, including demographics, preoperative evaluation, surgical invasiveness, ASA grade, anesthetic management, postoperative complications, and other relevant perioperative information. Body mass index (BMI) cut-off points were $30 \mathrm{~kg} / \mathrm{m}^{2}$ in consistent with the World Health Organization BMI diagnosis of obese. ${ }^{18}$ Bradycardia was defined as the baseline heartbeat $<50$ beats/min when the patient was awake and calm. ${ }^{19}$ Tachycardia was defined as the baseline heartbeat $>100$ beats/min when the patient was awake and calm. ${ }^{20}$ Hypertension was diagnosed if systolic blood pressure $(\mathrm{SBP}) \geq 130 \mathrm{mmHg}$ or diastolic blood pressure (DBP) $\geq 80$ mmHg. $^{21}$ Hypertension without regular treatment was defined as discontinuous antihypertensive treatment without regular monitor and medications, occasional antihypertensive treatment only if self-conscious discomfort, no antihypertensive drugs or no awareness of the diagnosis of hypertension until admission.

\section{Outcomes}

The primary outcome was the occurrence of at least one of the PCCs intraoperatively or within 30 days postoperatively. PCCs were defined as acute coronary syndrome (ACS), HF, new-onset severe arrhythmia, nonfatal cardiac arrest, and cardiac death. ${ }^{22-27}$ ACS included ST-elevation myocardial infarction (STEMI) and non-ST-elevation acute coronary syndrome (NSTE-ACS). NSTE-ACS could be further subdivided into non-ST-elevation MI and unstable angina according to the cardiac biomarkers. Diagnosis of MI requires a cTnI rise above the 99th percentile, accompanied by chest pain, ST-segment changes or new-onset left bundle branch block, ventricular wall motion abnormalities, or angiography confirmation. ${ }^{25} \mathrm{HF}$ was diagnosed mainly by active clinical symptoms or physical examination findings of dyspnea, orthopnea, peripheral edema, jugular venous distention, rales, third heart sound, or chest x-ray with pulmonary vascular redistribution or pulmonary edema. ${ }^{16,24}$ New-onset severe arrhythmia was defined as ECG changes needing to be treated with drug or electrical conversion, including malignant ventricular arrhythmia (ventricular tachycardia or ventricular fibrillation), atrial flutter or atrial fibrillation (AF), atrioventricular block (second-degree type II or third-degree), or frequent ventricular premature contractions. Cardiac arrest was defined as the loss of circulation prompting resuscitation requiring chest compressions, defibrillation, or both. ${ }^{26}$ Cardiac death was defined as death with known fatal cardiac conditions, autopsy identified cardiac or vascular anomaly or any death with no obvious extra-cardiac cause could be established. $^{27}$ PCCs were recorded if any of these complications occurred. The first occurred cardiac complications would be recorded if two or more types of PCCs happened in succession. The exact time when the PCCs were developing was also recorded.

\section{Statistical Analysis}

Categorical variables were presented as numbers (\%), and continuous variables were presented as the mean \pm standard deviation (SD) or median and interquartile range (IQR), depending on the distribution. A chi-square analysis was used between groups with and without PCCs to select possible risk factors of PCCs, and each variable showing a significant difference would enter the multivariate logistics regression analysis (method: Enter) to identify the independent risk factors. Simultaneously, the multivariate Cox regression model was used to estimate the independent predictors of PCCs. For the independent risk factors identified by both of the methods, the incidence of PCCs overtime was shown by the KaplanMeier survival method and the difference between the two groups was evaluated with a stratified Log-rank test. The significance level was set at a two-sided $P$ value less than 0.05 for all statistical tests. Statistical analyses were performed using SPSS 23.0 (IBM Inc., New York, USA).

\section{Results \\ Demographics}

Over the 16-year study period, 547 patients with CAD over 80 years old undergoing noncardiac surgeries were included in this retrospective analysis (Figure 1). The median age was 82 (IQR; 81, 84) years. The demographics and types of surgery of the 547 patients are shown in Table 1. 


\section{Perioperative Cardiac Complications}

Overall 106 (19.4\%) patients experienced at least one PCC in the included 547 patients (5 patients intraoperatively, 99 patients postoperatively, and 2 patients experienced complications both intraoperatively and postoperatively), among whom $15(2.7 \%)$ patients died within 30 days after surgery. $23(4.2 \%)$ patients experienced more than one type of PCCs successively. Among the 60 ACS cases diagnosed, 6(10.0\%) cases were STEMI, and 54 (90.0\%) cases were NSTE-ACS. 25 patients suffered new-onset severe arrhythmia, including $17(68.0 \%)$ cases of AF or atrial flutter, 5 (20.0\%) cases of paroxysmal supraventricular tachycardias and $3(12.0 \%)$ cases of other types. The details of PCCs incidence are shown in Table 2.

The majority of complications $(81,76.4 \%)$ occurred within the first 3 days after surgery, while 41 (38.7\%) developed within the first $24 \mathrm{~h}$ postoperatively. 25 patients experienced delayed PCCs (ranged 4 to 13 days postoperatively, median 7 days), including $12(48.0 \%)$ cases of HF, 10 (40.0\%) cases of ACS and $3(12.0 \%)$ cases of new-onset severe arrhythmia.

\section{Independent Risk Factors of PCCs}

Table 3 shows the Chi-square analyses of possible risk factors for PCCs. 22 variables $(P<0.05)$ were included in

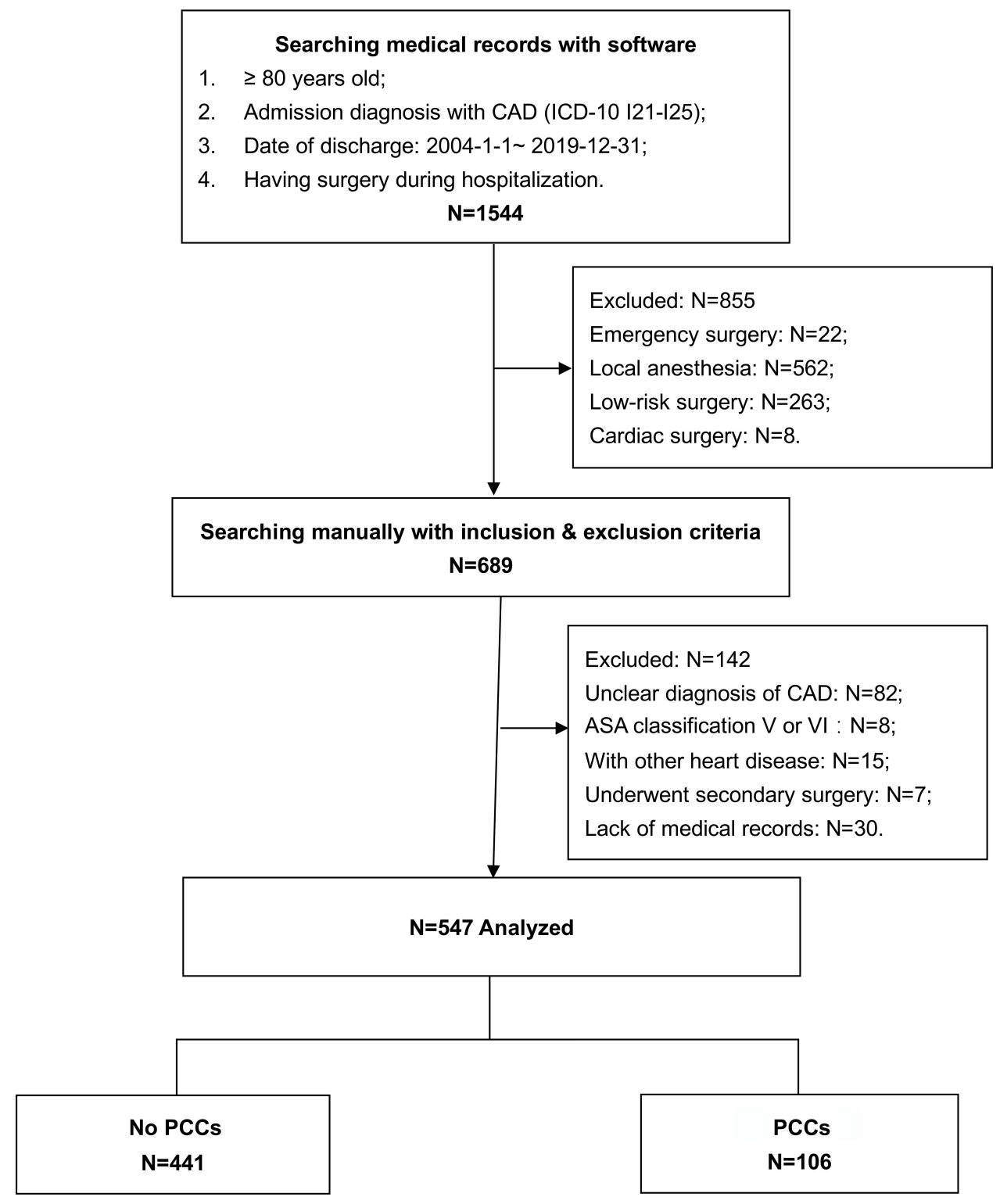

Figure I Flow chart showing patients enrolment and analysis.

Abbreviations: ASA, American Society of Anesthesiologists; CAD, coronary artery disease; ICD, international classification of diseases; PCCs, perioperative cardiac complications. 
Table I Demographics and Types of Surgery of the Study Population

\begin{tabular}{|c|c|}
\hline Variables & Total $(\mathrm{N}=547)$ \\
\hline Demographic & \\
\hline Age (years) & $82[8 I, 84]$ \\
\hline Male & $283(5 \mid .7)$ \\
\hline BMI $\left(k g / m^{2}\right)$ & $23.34 \pm 3.73$ \\
\hline $\begin{array}{l}\text { Smoking status } \\
\text { Never smoked } \\
\text { Current smoked } \\
\text { Former smoked }\end{array}$ & $\begin{array}{l}396(72.4) \\
68(12.4) \\
83(15.2)\end{array}$ \\
\hline $\begin{array}{l}\text { Comorbidities } \\
\text { HTN } \\
\text { Diabetes } \\
\text { HF } \\
\text { Arrhythmia } \\
\text { Cerebral infarction } \\
\text { Cerebral/peripheral vascular disease } \\
\text { COPD/Asthma }\end{array}$ & $\begin{array}{l}377(68.9) \\
157(28.7) \\
33(6.0) \\
199(36.4) \\
103(18.8) \\
180(32.9) \\
82(15.0)\end{array}$ \\
\hline METs $<4$ & $96(17.6)$ \\
\hline $\begin{array}{l}\text { ASA classification } \\
\text { II } \\
\text { III } \\
\text { IV }\end{array}$ & $\begin{array}{l}276(50.5) \\
259(47.3) \\
12(2.2)\end{array}$ \\
\hline $\begin{array}{l}\text { NYHA classification } \\
\text { I-II } \\
\text { III-IV }\end{array}$ & $\begin{array}{l}462(84.5) \\
85(15.5)\end{array}$ \\
\hline $\begin{array}{l}\text { Types of surgery } \\
\text { Main vascular procedures } \\
\text { Peripheral vascular procedures } \\
\text { Thoracic surgeries } \\
\text { Abdominal surgeries } \\
\text { Orthopedic surgeries } \\
\text { Head and neck surgeries } \\
\text { Other types of surgery } \\
\text { Duration of operation (min) [IQR] }\end{array}$ & $\begin{array}{l}35(6.4) \\
22(4.0) \\
23(4.2) \\
220(40.2) \\
177(32.4) \\
30(5.5) \\
40(7.3) \\
115[81,163.5]\end{array}$ \\
\hline
\end{tabular}

Notes: Results presented as mean \pm SD, median [IQR], or $n(\%)$

Abbreviations: ASA, American Society of Anesthesiologists; BMI, body mass index (weight/height ${ }^{2}$ ); COPD, chronic obstructive pulmonary disease; HF, heart failure; HTN, hypertension; IQR, interquartile range; METs, metabolic equivalents; NYHA, New York Heart Association; SD, standard deviation.

the multivariate logistic regression and multivariate Cox regression analysis. Among them, 8 independent risk factors were identified and found to be the same in both regression analysis: age $\geqq 85$ years; $\mathrm{BMI} \geqq 30 \mathrm{~kg} / \mathrm{m}^{2}$; history of angina within 6 months; metabolic equivalents (METs) <4; HTN without regular treatment; preoperative ECG ST-segment or T wave abnormality; anesthesia time
Table 2 Number of Patients with PCCs

\begin{tabular}{|l|l|l|l|}
\hline PCCs & N & $\begin{array}{l}\text { Percentage in } \\
\text { PCCs (\%) }\end{array}$ & $\begin{array}{l}\text { Percentage in } \\
\text { Total (\%) }\end{array}$ \\
\hline $\begin{array}{c}\text { ACS } \\
\text { STEMI } \\
\text { NSTE-ACS }\end{array}$ & $\begin{array}{l}60 \\
6\end{array}$ & $\begin{array}{l}56.6 \\
5.7 \\
50.9\end{array}$ & $\begin{array}{l}11.0 \\
1.1 \\
9.9\end{array}$ \\
\hline Heart failure & 21 & 19.8 & 3.8 \\
\hline $\begin{array}{c}\text { New-onset severe } \\
\text { arrhythmia } \\
\text { AF or atrial } \\
\text { flutter } \\
\begin{array}{c}\text { PSVT } \\
\text { Other types of } \\
\text { arrhythmia }\end{array}\end{array}$ & 25 & 23.6 & 4.6 \\
\hline $\begin{array}{l}\text { Nonfatal cardiac } \\
\text { arrest }\end{array}$ & 0 & 0 & 3.1 \\
\hline Total PCCs & 106 & 100.0 & 0.9 \\
\hline Cardiac death & 15 & 14.2 & 0.5 \\
\hline
\end{tabular}

Notes: 23 patients experienced more than one PCC successively and only the first occurred PCCs were recorded as the type of PCCs.

Abbreviations: ACS, acute coronary syndrome; AF, atrial fibrillation; NSTE-ACS, non-ST-elevation acute coronary syndromes; PCCs, perioperative cardiac complications; PSTV, paroxysmal supraventricular tachycardias; STEMI, ST-elevation myocardial infarction.

$>3 \mathrm{~h}$ and drainage $\geqq 200 \mathrm{~mL}$ within $24 \mathrm{~h}$ postoperatively (Table 4). The Kaplan-Meier curves of the 8 independent risk factors with a stratified Log-rank test are shown in Figure 2.

\section{Discussion}

The purpose of the study was to evaluate the PCCs incidence and risk factors of noncardiac surgery in patients over 80 years with CAD. The incidence of PCCs in the oldest-old patients with CAD undergoing noncardiac surgery was $19.4 \%$. Our study revealed eight independent risk factors (age $\geqq 85$ years, BMI $\geqq 30 \mathrm{~kg} / \mathrm{m}^{2}$, history of angina within 6 months, METs $<4$, HTN without regular treatment, preoperative ECG ST-T abnormality, anesthesia time $>3 \mathrm{~h}$, and drainage $\geqq 200 \mathrm{~mL}$ within $24 \mathrm{~h}$ postoperatively) associated with an increased risk for PCCs.

The incidence of PCCs exceeded significantly in the oldest-old population, compared to only $1.4-3.9 \%$ cardiac complication occurrence rate in the general population. ${ }^{28}$ With the number of patients undergoing major noncardiac surgery increasing, both the average age of patients and cardiac comorbidities are also increasing. ${ }^{29}$ In a prospective large-scale study, CAD history and age $\square 75$ were both 
Table 3 Comparisons of Variables Between Patients with and without PCCs

\begin{tabular}{|c|c|c|c|c|c|}
\hline Variables & $\begin{array}{l}\text { Patients without PCCs } \\
(n=441)\end{array}$ & $\begin{array}{l}\text { Patients with PCCs } \\
(n=106)\end{array}$ & $\chi^{2}$ & OR & P-value \\
\hline Age $\geqq 85$ years & $97(22.0)$ & $38(35.8)$ & 8.823 & 1.982 & 0.003 \\
\hline Sex $=$ male & $234(53.1)$ & $49(46.2)$ & 1.599 & 0.760 & 0.206 \\
\hline $\mathrm{BMI} \geqq 30 \mathrm{~kg} / \mathrm{m}^{2}$ & $14(3.2)$ & $8(7.5)$ & 4.233 & 2.490 & 0.040 \\
\hline Smoking history & $119(27.0)$ & $32(30.2)$ & 0.439 & 1.170 & 0.508 \\
\hline Current smoking & $53(12.0)$ & $15(14.2)$ & 0.357 & 1.207 & 0.550 \\
\hline ASA classification III/IV & $209(47.4)$ & $62(58.5)$ & 4.211 & 1.564 & 0.040 \\
\hline NYHA classification III/IV & $65(14.7)$ & $20(18.9)$ & 1.110 & 1.346 & 0.292 \\
\hline History of CABG & $22(5.0)$ & $3(2.8)$ & 0.913 & 0.555 & 0.339 \\
\hline History of angioplasty & $82(18.6)$ & $20(18.9)$ & 0.004 & 1.018 & 0.948 \\
\hline History of MI & $75(I 7.0)$ & $28(26.4)$ & 4.949 & 1.752 & 0.026 \\
\hline History of MI within 6 months & $5(1.1)$ & $4(3.8)$ & 3.680 & 3.420 & 0.055 \\
\hline History of HF & $20(4.5)$ & $13(12.3)$ & 9.005 & 2.942 & 0.003 \\
\hline History of HF within 6 months & $15(3.4)$ & $10(9.4)$ & 7.131 & 2.958 & 0.008 \\
\hline History of angina within 6 months & $80(\mid 8.1)$ & $35(33.0)$ & 11.393 & 2.224 & 0.001 \\
\hline History of UA within 6 months & $22(5.0)$ & $15(14.2)$ & 11.375 & 3.139 & 0.001 \\
\hline METs $<4$ & $63(14.3)$ & $33(3 \mathrm{I} .1)$ & 16.761 & 2.712 & 0.000 \\
\hline HTN without regular treatment & $35(7.9)$ & $15(14.2)$ & 3.974 & 1.912 & 0.046 \\
\hline History of cerebral infarction & $83(18.8)$ & $20(18.9)$ & 0.000 & 1.003 & 0.991 \\
\hline $\begin{array}{l}\text { History of cerebral/peripheral vascular } \\
\text { disease }\end{array}$ & $136(30.8)$ & $44(4 \mid .5)$ & 4.407 & 1.592 & 0.036 \\
\hline History of diabetes & $122(27.7)$ & $35(33.0)$ & 1.197 & 1.289 & 0.274 \\
\hline Treatment with insulin & $40(9.1)$ & $14(13.2)$ & 1.644 & 1.526 & 0.200 \\
\hline Preoperative bradycardia & $\mathrm{I}(0.2)$ & I (0.9) & 1.205 & 4.190 & 0.272 \\
\hline Preoperative tachycardia & $7(1.6)$ & $6(5.7)$ & 6.111 & 3.720 & 0.013 \\
\hline Preoperative Hct $<37 \%$ & $221(50.1)$ & $68(64.2)$ & 6.758 & 1.781 & 0.009 \\
\hline Preoperative $\mathrm{Hb}<110 \mathrm{~g} / \mathrm{L}$ & $113(25.6)$ & $35(33.0)$ & 2.368 & 1.431 & 0.124 \\
\hline Preoperative $\mathrm{Ccr}<50 \mathrm{~mL} / \mathrm{min}$ & $246(55.8)$ & $76(71.7)$ & 8.940 & 2.008 & 0.003 \\
\hline Preoperative ECG arrhythmia & $138(3 \mid .3)$ & $34(32.1)$ & 0.024 & 1.037 & 0.876 \\
\hline Preoperative ECF AF & $30(6.8)$ & II (10.4) & 1.575 & 1.586 & 0.209 \\
\hline Preoperative ECG ST-T abnormality & $203(46.0)$ & $75(70.8)$ & 20.900 & 2.836 & 0.000 \\
\hline Preoperative ECG Q wave & $34(7.7)$ & $13(12.3)$ & 2.257 & 1.673 & 0.133 \\
\hline Preoperative EF $<50 \%$ & $13(2.9)$ & $5(4.7)$ & 0.840 & 1.630 & 0.359 \\
\hline Preoperative EF $<55 \%$ & $25(5.7)$ & $12(11.3)$ & 4.328 & 2.124 & 0.037 \\
\hline Preoperative RWMA & $62(14.1)$ & $23(21.7)$ & 3.800 & 1.694 & 0.051 \\
\hline Preoperative PAH & $30(6.8)$ & $3(2.8)$ & 2.379 & 0.399 & 0.123 \\
\hline Vascular surgery & $47(10.7)$ & $10(9.4)$ & 1.137 & 0.873 & 0.711 \\
\hline General anesthesia & $329(74.6)$ & $76(71.7)$ & 0.375 & 0.862 & 0.540 \\
\hline Intraoperative inhalation anesthetics & $303(68.7)$ & $71(67.0)$ & 0.118 & 0.924 & 0.731 \\
\hline Intraoperative nitrous oxide & $231(52.4)$ & $61(57.5)$ & 0.971 & 1.232 & 0.388 \\
\hline Blood loss $\geqq 500 \mathrm{~mL}$ & $69(15.6)$ & II (I0.4) & 1.900 & 0.624 & 0.168 \\
\hline Intraoperative blood transfusion & $83(18.8)$ & $25(23.6)$ & 1.224 & 1.331 & 0.269 \\
\hline Intraoperative blood transfusions $\geqq 500 \mathrm{~mL}$ & $36(8.2)$ & II (10.4) & 0.533 & 1.303 & 0.465 \\
\hline Operation time $>2.5 \mathrm{~h}$ & $|2|(27.4)$ & $40(37.7)$ & 4.364 & 1.603 & 0.037 \\
\hline Anesthesia time $>3 \mathrm{~h}$ & $140(3 \mid .7)$ & $51(48.1)$ & 10.074 & 1.994 & 0.002 \\
\hline
\end{tabular}

(Continued) 
Table 3 (Continued).

\begin{tabular}{|c|c|c|c|c|c|}
\hline Variables & $\begin{array}{l}\text { Patients without PCCs } \\
(n=44 I)\end{array}$ & $\begin{array}{l}\text { Patients with PCCs } \\
(n=106)\end{array}$ & $\chi^{2}$ & OR & P-value \\
\hline Intraoperative hypotension & $60(13.6)$ & $27(25.5)$ & 8.997 & 2.170 & 0.003 \\
\hline Intraoperative hypoxia & $2(0.5)$ & $3(2.8)$ & 5.330 & 6.393 & 0.021 \\
\hline Admitted into ICU postoperatively & $247(56.0)$ & $79(74.5)$ & 12.127 & 2.298 & 0.000 \\
\hline Drainage $\geqq 200 \mathrm{~mL}$ within $24 \mathrm{~h}$ & $63(14.3)$ & $27(25.5)$ & 7.779 & 2.051 & 0.005 \\
\hline
\end{tabular}

Notes: BMI classifications was consistent with the World Health Organization BMI cut-off points of Obese; bradycardia was defined as the baseline heartbeat $<50$ beats/min when the patient was awake and calm; tachycardia was defined as the baseline heartbeat $>100$ beats/min when the patient was awake and calm. Results were presented as $n$ (\%). Abbreviations: AF, atrial fibrillation; ASA, American Society of Anesthesiologists; BMl, body mass index (weight/height ${ }^{2}$ ); CABG, coronary artery bypass grafting; Ccr, creatinine clearance rate; ECG, electrocardiograph; EF, ejection fraction; Hb, hemoglobin; Hct, hematocrit; HF, heart failure; HTN, hypertension; ICU, intensive care unit; METs, metabolic equivalents; MI, myocardial infarction; NYHA, New York Heart Association; OR, odds ratio; PAH, pulmonary arterial hypertension; PCCs, perioperative cardiac complications; RWMA, regional wall motion abnormality; UA, unstable angina.

independent predictors of MI in noncardiac surgery, with $10.3 \%$ and $23.5 \%$ population attribute risk, respectively. ${ }^{7}$ We observed that the majority of the PCCs (76.4\%) occurred within $72 \mathrm{~h}$ after surgery, in agreement with the finding in the general population. ${ }^{30}$ So, the first $72 \mathrm{~h}$ after surgery should be a critical period for these populations with high risk, which demanded close monitoring to detect early PCCs.

ACS was the main type of PCCs, nearly all of which was NSTE-ACS. The mismatch between oxygen supply and demand, as well as coronary-artery thrombosis, are the classic mechanism of ACS. The catecholamine stress caused by trauma and pain increases the oxygen consumption of heart dramatically, as a hard shock for oldest-old patients, epically when hypovolemia, hypoxia, and electrolyte disturbances have all been implicated. ${ }^{13}$ Because of the effects of postoperative analgesia, patients may not experience chest pain. Moreover, in older and diabetic patients, autonomic dysfunction may cause ambiguity in presentation. ${ }^{30}$ Therefore, relying on classical symptoms alone could lead to a missed diagnosis of silent or non-specific ACS. Postoperative regular ECG monitoring and troponin screening with satisficing sensitivity should be routinely operated in the very-high-risk population. ${ }^{3}$

New-onset severe arrhythmia accounted for almost a quarter of PCCs in our study, and AF was the most common type (3.1\% in the study population). While the incidence of newly diagnosed postoperative AF is only $0.97 \%$ in a large retrospective study with 370,447 patients over 18 years of age. ${ }^{31}$ Though most AF resolve spontaneously, pulmonary artery pressure increases and tachycardia may cause myocardial ischemia through the loss of diastolic filling time and increased myocardial work. ${ }^{3}$

In this study, $20 \%$ of patients suffered new-onset HF as their first occurred PCCs, without patients who developed HF as a consequence of MI events. Moreover, HF tended to appear later than other PCCs. As a result of perioperative inappropriate fluid strategy, hypervolemia could increase left atrial pressure and finally lead to pulmonary edema. On the other hand, HF could also be secondary to other pathological changes, such

Table 4 Results Output of the Multivariate Logistics Regression and the Multivariate Cox Regression Analysis for Independent Risk Factors of PCCs

\begin{tabular}{|c|c|c|c|c|c|c|}
\hline \multirow[t]{2}{*}{ Variables } & \multicolumn{3}{|c|}{ Multivariate Logistics Regression } & \multicolumn{3}{|c|}{ Multivariate Cox Regression } \\
\hline & P-value & OR & $95 \% \mathrm{Cl}$ & P-value & HR & $95 \% \mathrm{Cl}$ \\
\hline Age $\geqq 85$ years & 0.014 & 2.002 & $1.149-3.490$ & 0.033 & 1.611 & $1.04-2.496$ \\
\hline $\mathrm{BMI} \geqq 30 \mathrm{~kg} / \mathrm{m}^{2}$ & 0.015 & 4.065 & $1.311-12.602$ & 0.022 & 2.489 & I.|39-5.44| \\
\hline History of angina within 6 months & 0.022 & 2.156 & $1.119-4.154$ & 0.029 & 1.792 & $1.061-3.027$ \\
\hline METs $<4$ & 0.027 & 1.987 & $\mathrm{I} .08 \mathrm{I}-3.655$ & 0.047 & 1.611 & $1.007-2.579$ \\
\hline HTN without regular treatment & 0.018 & 2.602 & $1.181-5.732$ & 0.041 & 1.869 & $1.027-3.400$ \\
\hline Preoperative ECG ST-T abnormality & 0.000 & 2.546 & $1.511-4.290$ & 0.002 & 1.981 & $1.275-3.076$ \\
\hline Anesthesia time $>3 \mathrm{~h}$ & 0.004 & 3.620 & $|.52|-8.6 \mid 4$ & 0.004 & 2.767 & I.397-5.48। \\
\hline Drainage $\geqq 200 \mathrm{~mL}$ within $24 \mathrm{~h}$ & 0.005 & 2.356 & $1.29 \mid-4.298$ & 0.013 & 1.819 & $1.135-2.914$ \\
\hline
\end{tabular}

Abbreviations: BMI, body mass index (weight/height ${ }^{2}$ ); $\mathrm{Cl}$, confidence interval; ECG, electrocardiograph; HTN, hypertension; HR, hazard ratio; METs, metabolic equivalents; OR, odds ratio; PCCs, perioperative cardiac complications. 


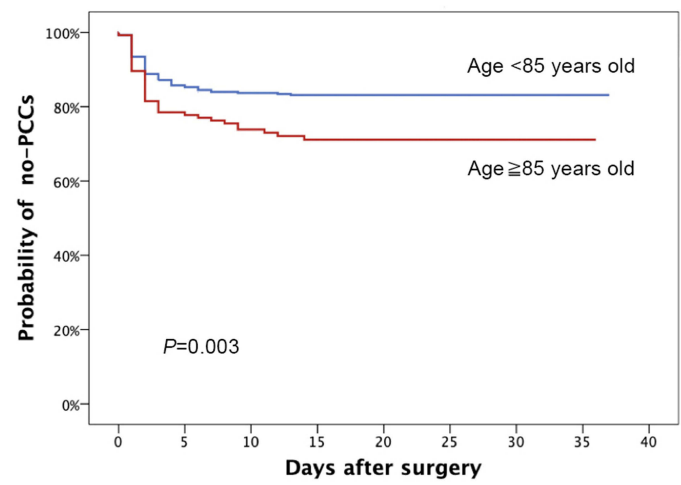

A

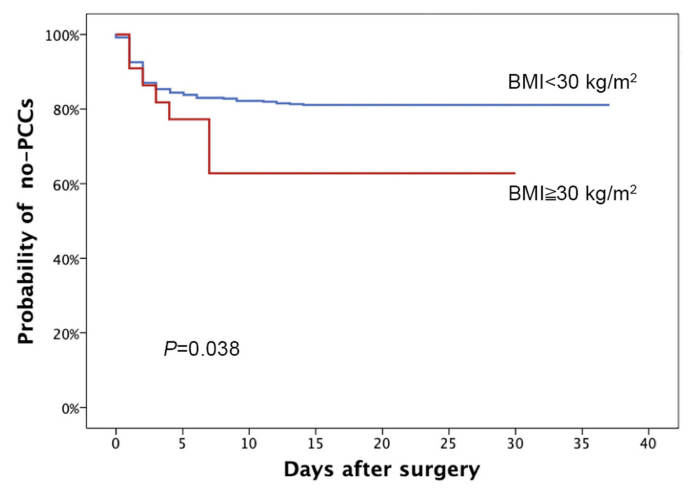

B
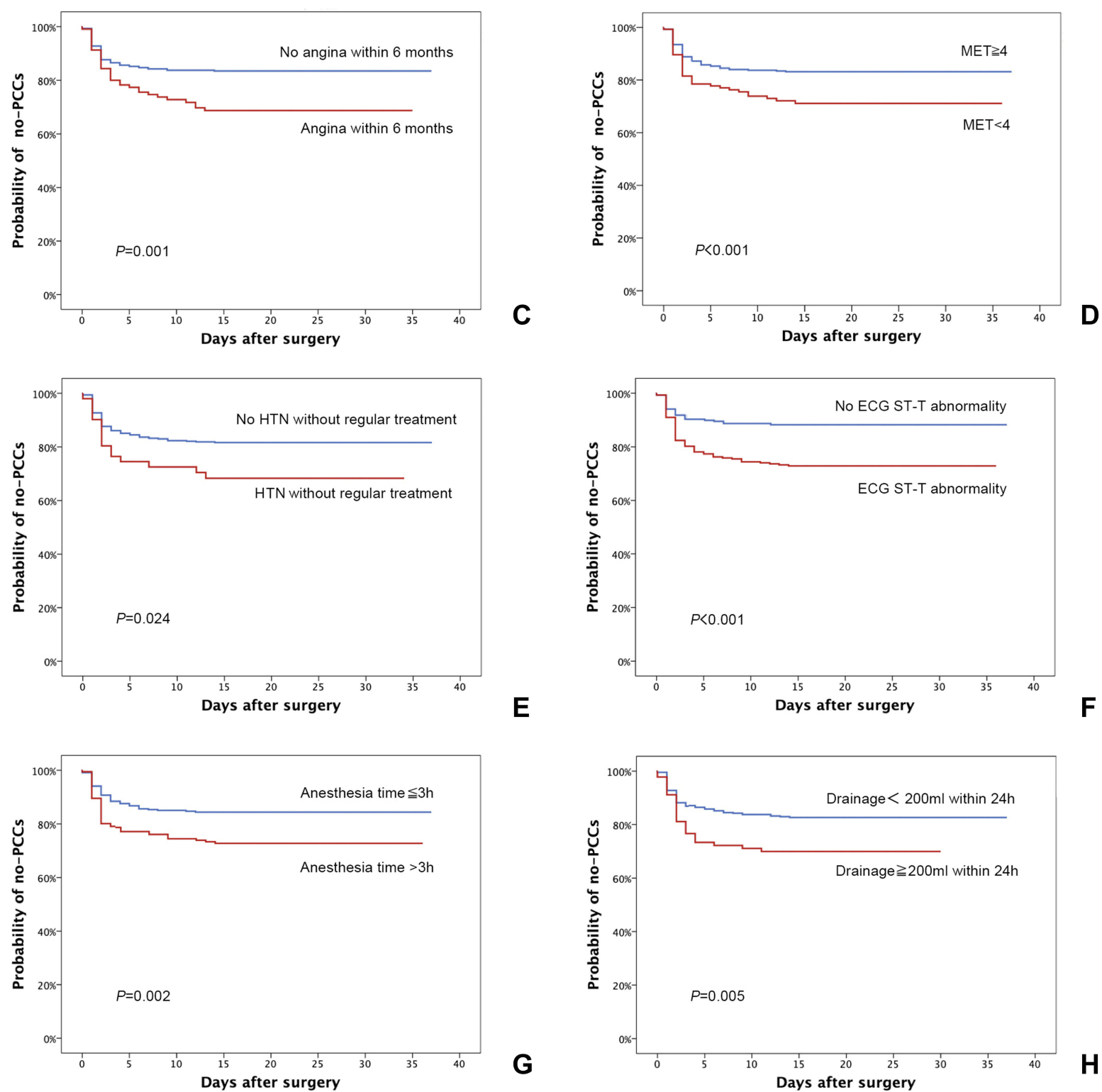

$\mathbf{F}$

Figure 2 The Kaplan-Meier curves of probability of patients without PCCs for the eight independent risk factors (A) age $\geqq 85$ years; (B) BMI $\geqq 30 \mathrm{~kg} / \mathrm{m}^{2} ;(\mathbf{C})$ the history of angina within 6 months; (D) METs <4; (E) HTN without regular treatment; (F) preoperative ECG ST-T abnormality; (G) anesthesia time $>3$ h; (H) drainage $\geqq 200 \mathrm{~mL}$ within 24 h postoperatively.

Abbreviations: BMI, body mass index (weight/height $\left.{ }^{2}\right)$; ECG, electrocardiograph; HTN, hypertension; METs, metabolic equivalents; PCCs, perioperative cardiac complications. 
as perioperative lung injury, renal impairment, and sepsis. ${ }^{3}$ Regardless of etiology, postoperative HF has 30-day mortality of $8 \% .^{32}$ It has been suggested to use goal-directed fluid therapy and cardiac output monitoring optimizing stroke volume for elderly patients. ${ }^{33}$

Some of the study revealed eight independent risk factors have been reported as risk factors in multiple studies and described in clinical guidelines. ${ }^{2,16,34,35}$ Although all subjects of this study were elderly over 80 years, age was still an independent predictor of PCCs. The incidence of PCCs increased significantly for patients over 85 years compared to those between 80 and 85 years. The tolerance to the overactivation of the sympathetic nervous system and hemodynamic stress is impaired with age. In a prospective study of elderly patients ( $\geqq 60$ years) undergoing elective major noncardiac surgery, advanced age was also recognized as an important risk factor for postoperative adverse cardiovascular events. ${ }^{36}$ Furthermore, advanced age might continue influencing the prognosis for patients who experienced PCCs. Aged 75 or older, was an independent predictor of 30-day mortality among patients who suffered MI after noncardiac surgery. ${ }^{8}$

Preoperative ECG ST-T abnormality was an independent risk factor of PCCs in this study. The prognostic significance of ST-segment abnormalities in addition to clinical characteristics had been identified. ${ }^{37}$ A prognostic study with 172 CAD patients undergoing major noncardiac surgery demonstrated that ST depressions were independent predictors of all-cause mortality in two years after surgery. ${ }^{38}$ In addition, more attention should also be paid to other ECG variables, such as QT interval duration which is a predictor of fatal ventricular arrhythmia and sudden cardiac death in smokers, hypertensive, overweight and obese patients, ${ }^{39}$ as well as in patients with renal failure. ${ }^{40}$ The implications of abnormalities on the preoperative 12-lead ECG increase with patient age and with risk factors for CAD. ${ }^{16}$ Therefore, ECG monitoring may be extremely important in oldest-old patients undergoing noncardiac surgery, enabling assessment of PCCs risk.

We found out that higher rates of PCCs are associated with angina within 6 months, which was consistent with the previous report. ${ }^{4}$ The stability and timing of a recent myocardial event impact the incidence of perioperative morbidity and mortality. ACC/AHA guidelines recommend at least a 60-day interval between an ACS and elective noncardiac surgery. ${ }^{16}$ As we know coronary revascularization before noncardiac surgery is generally indicated in unstable CAD. ${ }^{4}$ However, there were no recommendations for patients over 80 years old. And it would be very meaningful to investigate the benefit of coronary revascularization for oldest-old patients with unstable angina or preoperative ECG ST-T abnormality in future prospective cohort trials.

We found out that hypertension without regular treatment was an independent predictor for PCCs. Hypertension is considered as a classical cardiovascular risk factor in non-cardiac surgery. ${ }^{4}$ Increased stiffness of the great vessels and decreased cardiovascular reserve capacity are hallmarks of aging, especially for hypertension patients without regular control. ${ }^{41}$ One orthopedic retrospective study enrolled 46,322 patients demonstrated that age $>80$ years, a history of cardiac disease and hypertension requiring medication were significant risk factors for developing PCCs following primary unilateral total knee arthroplasty and total hip arthroplasty. ${ }^{42}$ But there are also valid concerns that strict control of BP may increase the risk of hypotension in the geriatric population older than 80 years. Recently, an analysis performed that the lowest mortality was found in individuals with SBP of $135-154 \mathrm{mmHg}$ in aged 80 years and older, suggesting it as an optimal range of BP. ${ }^{43}$

In our study, drainage $\geqq 200 \mathrm{~mL}$ within $24 \mathrm{~h}$ postoperatively was found to be an independent risk factor of PCCs. Hypovolemia induced by postoperative bleeding and insufficient fluid volume could increase myocardial work, and further aggravate the mismatch between oxygen supply and demand, which is the prominent pathogenesis on perioperative ACS.

Several related chronic conditions like cerebrovascular disease, diabetes mellitus, and renal dysfunction and other risk factors in the general population were not independent predictors of PCCs in this study. ${ }^{2,16}$ Partially because these factors are the surrogates for an unknown cardiac condition. This could also be attributed to the optimization of patients before elective surgery and improvements in the surgical procedure in the recent 10 years.

The main limitation of our study is the relatively small number of patients. As a retrospective study, some preoperative information was unavailable, including cTnI levels, ${ }^{44}$ electrolyte imbalances potential related to arrhythmia, and serum biomarkers of atherosclerosis, such as inflammatory biomarkers (fibrinogen, high sensitivity $\mathrm{C}$ reactive protein) and biomarkers of oxidative stress (especially advanced glycation end-products). ${ }^{45}$ Several other ECG variables such as $\mathrm{P}$-wave duration and dispersion as predictors of AF were not analyzed. $^{46}$ And we could not comment on the role of preoperative medical management in modifying the risk of PCCs. Postoperative troponin was tested only if clinical or ECG evidence of PCCs, which might lead to a missed diagnosis of silent MI. Moreover, asymptomatic silent troponin level elevation alone is strongly associated with mortality. ${ }^{47}$ More prospective studies should be designed to evaluate risk factors and 
prophylactic cardiac interventions, and make comprehensive predictive stratification models that allow for better preoperative optimization as to minimize PCCs.

\section{Conclusion}

The incidence of PCCs was high for the oldest-old patients with CAD undergoing noncardiac surgery, among which ACS was the main type. The independent predictive risk factors of PCCs for this population included age $\geqq 85$ years; BMI $\geqq 30 \mathrm{~kg} / \mathrm{m}^{2}$; the history of angina within 6 months; METs $<4$; HTN without regular treatment; preoperative ECG ST-T abnormality; anesthesia time $>3 \mathrm{~h}$ and drainage $\geqq 200 \mathrm{~mL}$ within $24 \mathrm{~h}$ postoperatively. Our study indicated that comprehensive preoperative evaluation and optimization (eg, angina, hypertension, cardiopulmonary function), shortened anesthesia time, skilled surgical techniques and exact hemostasis, and regular postoperative monitoring may help to reduce PCCs. More prospective multicenter investigations are required to further clarify the risk stratification and prognostic value of PCCs in this population.

\section{Funding}

Grant support: supported by Chinese Academy of Medical Sciences Innovation Fund for Medical Sciences (CIFMS) (2016-I2M-3-024).

\section{Disclosure}

The authors report no conflicts of interest in this work.

\section{References}

1. Weiser TG, Haynes AB, Molina G, et al. Size and distribution of the global volume of surgery in 2012. Bull World Health Organ. 2016;94 (3):201-209F. doi:10.2471/blt.15.159293

2. Kristensen SD, Knuuti J, Saraste A, et al. 2014 ESC/ESA guidelines on non-cardiac surgery: cardiovascular assessment and management: the joint task force on non-cardiac surgery: cardiovascular assessment and management of the European Society of Cardiology (ESC) and the European Society of Anaesthesiology (ESA). Eur Heart J. 2014;35 (35):2383-2431. doi:10.1093/eurheartj/ehu282

3. Sellers D, Srinivas C, Djaiani G. Cardiovascular complications after non-cardiac surgery. Anaesthesia. 2018;73(Suppl 1):34-42. doi:10.1111/anae.14138

4. Devereaux PJ, Sessler DI, Longo DL. Cardiac complications in patients undergoing major noncardiac surgery. $N$ Engl $J$ Med. 2015;373(23):2258-2269. doi:10.1056/nejmra1502824

5. Elsiwy Y, Jovanovic I, Doma K, Hazratwala K, Letson H. Risk factors associated with cardiac complication after total joint arthroplasty of the hip and knee: a systematic review. J Orthop Surg Res. 2019;14 (1):1-12. doi:10.1186/s13018-018-1058-9

6. Hansen PW, Gislason GH, Jørgensen ME, et al. Influence of age on perioperative major adverse cardiovascular events and mortality risks in elective non-cardiac surgery. Eur J Intern Med. 2016;35:55-59. doi:10.1016/j.ejim.2016.05.028
7. Devereaux PJ, Sessler DI, Leslie K, et al. Clonidine in patients undergoing noncardiac surgery. $N$ Engl J Med. 2014;370 (16):1504-1513. doi:10.1056/NEJMoa1401106

8. Botto F, Alonso-Coello P, Chan MTV, et al. Myocardial injury after noncardiac surgery: a large, international, prospective cohort study establishing diagnostic criteria, characteristics, predictors, and 30-day outcomes. Anesthesiology. 2014;120(3):564-578. doi:10.1097/ ALN.0000000000000113

9. Xu L, Yu C, Jiang J, et al. Major adverse cardiac events in elderly patients with coronary artery disease undergoing noncardiac surgery: a multicenter prospective study in China. Arch Gerontol Geriatr. 2015;61(3):503-509. doi:10.1016/j.archger.2015.07.006

10. United Nations, Department of Economic and Social Affairs. Population division (2015). World population ageing 2015 (ST/ESA/ SER.A/390). Available from: http://www.un.org/en/development/desa/ population/publications/pdf/ageing/WP A2015_Report.pdf.

11. Grubey JS, Raji Y, Duke WS, Terris DJ. Outpatient thyroidectomy is safe in the elderly and super-elderly. Laryngoscope. 2018;128 (1):290-294. doi:10.1002/lary.26707

12. World Health Organization. China country assessment report on ageing and health. WHO library cataloguing-in-publication data 2015 (ISBN 978924150931 2). Available from: https://www.who.int/ ageing/publications/china-country-assessment/en/.

13. Nanayakkara S, Marwick TH, Kaye DM. The ageing heart: the systemic and coronary circulation. Heart. 2018;104(5):370-376. doi:10.1136/heartjnl-2017-312114

14. Jeong O, Park YK, Jung MR, Ryu SY. Compliance with guidelines of enhanced recovery after surgery in elderly patients undergoing gastrectomy. World J Surg. 2017;41(4):1040-1046. doi:10.1007/ s00268-016-3845-y

15. Mitsutake S, Ishizaki T, Teramoto C, Shimizu S, Ito H. Patterns of co-occurrence of chronic disease among older adults in Tokyo, Japan. Prev Chronic Dis. 2019;16:e1-e11. doi:10.5888/pcd16.180170

16. Fleisher LA, Fleischmann KE, Auerbach AD, et al. 2014 ACC/AHA guideline on perioperative cardiovascular evaluation and management of patients undergoing noncardiac surgery: executive summary. Circulation. 2014;130(24):2215-2245. doi:10.1161/CIR.0000000000000105

17. Fihn SD, Gardin JM, Abrams J, et al. 2012 ACCF/AHA/ACP/AATS/ $\mathrm{PCNA} / \mathrm{SCAI} / \mathrm{STS}$ guideline for the diagnosis and management of patients with stable ischemic heart disease: executive summary. Circulation. 2012;126(25):3097-3137. doi:10.1161/CIR.0b013e3182776f83

18. Barba C, Cavalli-Sforza T, Cutter J, et al. WHO expert consultation. Appropriate body-mass index for Asian populations and its implications for policy and intervention strategies. Lancet. 2004;363 (9403):157-163. doi:10.1016/S0140-6736(03)15268-3

19. Kusumoto FM, Schoenfeld MH, Barrett C, et al. 2018 ACC/AHA/ HRS guideline on the evaluation and management of patients with bradycardia and cardiac conduction delay. Circulation. 2019;140(8): e382-e482. doi:10.1161/CIR.0000000000000628

20. Page RL, Joglar JA, Caldwell MA, et al. 2015 ACC/AHA/HRS guideline for the management of adult patients with supraventricular tachycardia: a report of the American College of Cardiology/ American Heart Association task force on clinical practice guidelines and the heart rhythm society. J Am Coll Cardiol. 2016;67(13):e27e115. doi:10.1016/j.jacc.2015.08.856

21. Whelton PK, Carey RM, Aronow WS, et al. 2017 ACC/AHA/AAPA/ $\mathrm{ABC} / \mathrm{ACPM} / \mathrm{AGS} / \mathrm{APhA} / \mathrm{ASH} / \mathrm{ASPC} / \mathrm{NMA} / \mathrm{PCNA}$ guideline for the prevention, detection, evaluation, and management of high blood pressure in adults. J Am Coll Cardiol. 2017;71(19):e127-e248. doi:10.1016/j.jacc.2017.11.006

22. O'Gara PT, Kushner FG, Ascheim DD, et al. 2013 ACCF/AHA guideline for the management of st-elevation myocardial infarction: executive summary: a report of the American College of Cardiology Foundation/American Heart Association task force on practice guidelines. Circulation. 2013;127(4):529-555. doi:10.1161/ CIR.0b013e3182742c 84 
23. Amsterdam EA, Wenger NK, Brindis RG, et al. 2014 AHA/ACC guideline for the management of patients with non-st-elevation acute coronary syndromes: a report of the American College of Cardiology/American Heart Association task force on practice guidelines. J Am Coll Cardiol. 2014;64(24):e139-e228. doi:10.1016/j.jacc.2014.09.017

24. Yancy CW, Jessup M, Bozkurt B, et al. 2013 ACCF/AHA guideline for the management of heart failure: a report of the American College of Cardiology Foundation/American Heart Association task force on practice guidelines. J Am Coll Cardiol. 2013;62(16):e147-e239. doi:10.1016/j.jacc.2013.05.019

25. Thygesen K, Alpert JS, Jaffe AS, et al. Third universal definition of myocardial infarction. Circulation. 2012;126(16):2020-2035. doi:10.1161/CIR.0b013e31826e1058

26. Andersen LW, Holmberg MJ, Berg KM, et al. In-hospital cardiac arrest: a review. JAMA. 2019;321(12):1200-1210. doi:10.1001/ jama.2019.1696

27. Priori SF, Blomström-Lundqvist C, Mazzanti A, et al. 2015 ESC guidelines for the management of patients with ventricular arrhythmias and the prevention of sudden cardiac death: the task force for the management of patients with ventricular arrhythmias and the prevention of sudden cardiac death of the European Society of Cardiology (ESC). Endorsed by: association for European paediatric and congenital cardiology (AEPC). Eur Heart J. 2015;36 (41):2793-2867. doi:10.1093/eurheartj/ehv316

28. Patel AY, Eagle KA, Vaishnava P. Cardiac risk of noncardiac surgery. $J$ Am Coll Cardiol. 2015;66(19):2140-2148. doi:10.1016/j. jacc.2015.09.026

29. Siddiqui NF, Coca SG, Devereaux PJ, et al. Secular trends in acute dialysis after elective major surgery - 1995 to 2009. Cmaj. 2012;184 (11):1237-1245. doi:10.1503/cmaj.110895

30. Sunny JC, Kumar D, Kotekar N, Desai N. Incidence and predictors of perioperative myocardial infarction in patients undergoing non-cardiac surgery in a tertiary care hospital. Indian Heart J. 2018;70(3):335-340. doi:10.1016/j.ihj.2017.08.010

31. Bhave PD, Goldman LE, Vittinghoff E, Maselli J, Auerbach A. Incidence, predictors, and outcomes associated with postoperative atrial fibrillation after major noncardiac surgery. Am Heart J. 2012;164(6):918-924. doi:10.1016/j.ahj.2012.09.004

32. Van Diepen S, Bakal JA, Mcalister FA, Ezekowitz JA. Mortality and readmission of patients with heart failure, atrial fibrillation, or coronary artery disease undergoing noncardiac surgery: an analysis of 38,047 patients. Circulation. 2011;124(3):289-296. doi:10.1161/ CIRCULATIONAHA.110.011130

33. Ryu T, Song SY. Perioperative management of left ventricular diastolic dysfunction and heart failure: an anesthesiologist's perspective. Korean J Anesthesiol. 2017;70(1):3-12. doi:10.4097/kjae.2017.70.1.3
34. Che L, Xu L, Huang Y, Yu C. Clinical utility of the revised cardiac risk index in older Chinese patients with known coronary artery disease. Clin Interv Aging. 2018;13:35-41. doi:10.2147/CIA.S144832

35. Cohen ME, Ko CY, Bilimoria KY, et al. Optimizing ACS NSQIP modeling for evaluation of surgical quality and risk: patient risk adjustment, procedure mix adjustment, shrinkage adjustment, and surgical focus. J Am Coll Surg. 2013;217(2):336-346. doi:10.1016/ j.jamcollsurg.2013.02.027

36. Gu Z, Sun C, Xiang D. Postoperative adverse cardiovascular events associated with leptin and adverse age after elective major non-cardiac surgery: an Asian single-center study. Med Sci Monit. 2018;24:2119-2125. doi:10.12659/msm.906797

37. Noordzij PG, Boersma E, Bax JJ, et al. Prognostic value of routine preoperative electrocardiography in patients undergoing noncardiac surgery. Am J Cardiol. 2006;97(7):1103-1106. doi:10.1016/j. amjcard.2005.10.058

38. Jeger RV, Probst C, Arsenic R, et al. Long-term prognostic value of the preoperative 12-lead electrocardiogram before major noncardiac surgery in coronary artery disease. Am Heart J. 2006;151 (2):508-513. doi:10.1016/j.ahj.2005.04.018

39. Mozos I, Filimon L. QT and Tpeak-Tend intervals in shift workers. J Electrocardiol. 2013;46(1):60-65. doi:10.1016/j.jelectrocard.2012. 10.014

40. Mozos I. Laboratory markers of ventricular arrhythmia risk in renal failure. Biomed Res Int. 2014;2014:509204. doi:10.1155/2014/509204

41. Hammond G, Rich MW. Hypertensive heart failure in the very old. Heart Fail Clin. 2019;15(4):477-485. doi:10.1016/j.hfc.2019.06.001

42. Belmont PJ, Goodman GP, Kusnezov NA, et al. Postoperative myocardial infarction and cardiac arrest following primary total knee and hip arthroplasty: rates, risk factors, and time of occurrence. J Bone Joint Surg Am. 2014;96(24):2025-2031. doi:10.2106/JBJS.N.00153

43. Delgado J, Masoli JAH, Bowman K, et al. Outcomes of treated hypertension at age 80 and older: cohort analysis of 79,376 individuals. J Am Geriatr Soc. 2017;65(5):995-1003. doi:10.1111/ jgs. 14712

44. Zhao BC, Liu WF, Deng QW, et al. Meta-analysis of preoperative high-sensitivity cardiac troponin measurement in non-cardiac surgical patients at risk of cardiovascular complications. Br J Surg. 2020;107 (2):e81-e90. doi:10.1002/bjs.11305

45. Tibaut M, Caprnda M, Kubatka P, et al. Markers of atherosclerosis: part 1 - serological markers. Heart Lung Circ. 2019;28(5):667-677. doi:10.1016/j.hlc.2018.06.1057

46. MozosI. Arrhythmia risk and obesity. J Mol Genet Med. 2014; S1:006. doi:10.4172/1747-0862.S1-006

47. Sessler DI, Devereaux PJ. Perioperative troponin screening. Anesth Analg. 2016;123(2):359-360. doi:10.1213/ANE.0000000000001450
Clinical Interventions in Aging

\section{Publish your work in this journal}

Clinical Interventions in Aging is an international, peer-reviewed journal focusing on evidence-based reports on the value or lack thereof of treatments intended to prevent or delay the onset of maladaptive correlates of aging in human beings. This journal is indexed on PubMed Central, MedLine, CAS, Scopus and the Elsevier
Bibliographic databases. The manuscript management system is completely online and includes a very quick and fair peer-review system, which is all easy to use. Visit http://www.dovepress.com/ testimonials.php to read real quotes from published authors. 